TEMAS DE ACTUALIDAD

Rev Chil Salud Pública 2019,

Vol 23(2): 157-160

\title{
LA FUERTE LUZ DE LA ESFERA PÚBLICA
}

\author{
THE BRIGHT LIGHT OF THE PUBLIC SPHERE
}

I.

Es evidente que los acontecimientos ocurridos en Chile obligan a una reflexión por parte de todos. En especial, por todos aquellos vinculados de alguna manera al mundo de lo público. Ciertamente por todos los vinculados directamente a la política como actividad principal y exclusiva: especialmente parlamentarios, miembros del gobierno, militantes comprometidos con los partidos políticos. Pero también por todos aquellos cuyas acciones tienen que ver con ámbitos de ejercicio colectivo. Estoy pensando en todos aquellos que tienen que ver con la formación de los ciudadanos (educadores de todo tipo); que tienen que ver con el bienestar de los ciudadanos (personal de salud, principalmente); que tienen que ver con el control de los ciudadanos, es decir con el registro y sanciones por todos nuestros pecados veniales y de los otros (obviamente policías, juzgados y fiscalías). Destaco 'ciudadanos' porque me interesa insistir en algo que tenemos en común: es la cosa pública lo que origina y está en el centro del conflicto.

Creo que todos tenemos cierta cuota de responsabilidad en lo ocurrido. La amplitud y la agresividad de la reacción de amplios sectores sociales nos sorprendió a todos; y que nos sorprendiera es la prueba misma de nuestra responsabilidad. ¿Cómo es posible que no lo presintiéramos? ¿Cómo no nos dimos cuenta de lo que se incubaba? Desde esta perspectiva sería interesante reflexionar acerca de nuestras tareas como instituciones académicas aquí y ahora. Sin embargo, en lo ocurrido hay algo nuevo, algo inédito, que nos obliga a reflexionar primero sobre el sentido político de estos acontecimientos. Y esa novedad tiene que ver con la profundidad de los cambios que se avisoran, que se insinuan, ¿que se prometen?

¿Por qué es nuevo? Es nuevo por la violencia. La habíamos visto en otras ocasiones; pero esa violencia era en algún grado limitada. Es nuevo igualmente por su carácter multitudinario. En las protestas anteriores manifestaban grupos importantes de la población, pero nunca se juntaba un millón doscientas o un millón cuatrocientas mil personas en una tarde. Es parte de la novedad también que todo esto ocurrió al margen de los partidos políticos. No había insignias partidistas en la manifestación, no había organizadores de los eventos, no había oradores en ellos. De hecho, los partidos políticos, anonadados, sacaron la voz solo varios días después del arranque del proceso.

\section{¿Qué pasó o qué ha estado pasando en estos días?}

Jorge Gaete A.

Editor Asociado

Revista Chilena de Salud Pública Escuela de Salud Pública
Irène Némirovsky, en una breve narracion publicada en 1938, se pregunta acerca de cuál es el instante exacto en el que nace una revolución. Recurriendo a sus recuerdos de niña en San Petersburgo, señala recordar cuando nacía la revolución de octubre: "Todos los que vieron de cerca la guerra o los disturbios lo conocen: to- 
dos le dan un nombre diferente a ese demonio, pero siempre tiene la misma cara, demacrado y loco, y aquellos que lo vieron una vez no lo olvidarán nunca más." Desde otro ángulo del mundo, Octavio Paz hace un recuerdo parecido al observar los rostros de los españoles derrotados de la Guerra Civil: "Quien ha visto la Esperanza, no la olvida. La busca bajo todos los cielos y entre todos los hombres. Y sueña que un día va a encontrarla de nuevo, no sabe dónde, acaso entre los suyos. En cada hombre late la posibilidad de ser o, más exactamente, de volver a ser, otro hombre." ¿Qué fue lo que hemos visto en las calles de Santiago? ¿El demonio o la esperanza? En cualquier caso, no lo olvidaremos.

\section{II.}

Es indudable que el 'estallido social', el 'despertar de Chile' o como quiera Ilamársele tiene que ver con el rompimiento de la forma en que se ha construido nuestra convivencia. Prácticamente desde la dictadura cívico-militar del 73 para acá, el modelo neoliberal parece ser la piedra de toque. Este neoliberalismo aceptado por moros y cristianos (con algo más de rigor, propuesto, promovido y celebrado por cristianos y tolerado por moros con una conciencia política digna de mayores estudios) ha provocado innumerables daños en estos más de cuarenta años: la transformación de toda la vida chilena en un ámbito propio para los negocios genera problemas para donde uno mire. Un librito digno de revisar es La Revolución Silenciosa de Joaquín Lavín, publicado en 1987 : como en pocos textos se puede apreciar el entusiasmo que suscitaba la modernidad propuesta por la dictadura y la forma segura y decidida en que se anticipaba el futuro esplendor de la república, el mismo que hoy está por los suelos.

Y en todos los ámbitos, es el mundo público (lo que es común a todos o lo que es de todos simplemente) el que resulta problemático. Todo se compra: obviamente el pan nuestro de cada día y todo lo que debe venir con él, pero también la educación y la salud, y la vivienda, pero se trabaja por sueldos que no permiten superar las líneas de probreza. En virtud del sagrado crecimiento, todo aprovechamiento de la tierra, agua y aire es bienvenido. Los negocios son el alma del país y en pro de ellos todo dinero que se pueda aportar a su buen funcionamiento es utilizado. Y todo esto en un marco de regulacio- nes mínimas. Resultado: un sistema de seguridad social que no es tal; utilidades desmesuradas para las grandes empresas financieras y pensiones inconcebiblemente bajas para nuestros jubilados. Como parte de los negocios, situaciones y acciones 'ideológicamente' falsas menudean y la justicia siempre discriminando...

Todo lo que se vende y por consiguiente se compra queda en el mundo de lo privado; entonces compras lo que puedes y te alegras o te resignas. El problema aparece cuando no se puede comprar. Y nos hemos pasado años y años regulando el manejo de lo público: hay pobreza y pobreza extrema, hay sectores vulnerables, hay bonos y subsidios, hay condiciones de salud con garantías explícitas de atención, hay beneficios para adultos mayores en el transporte público. Esta situación está al origen de una política de mínimos, de básicos o de primarios: sueldo mínimo, necesidades básicas, educación primaria, atención primaria, canasta básica, y así sucesivamente. Todo apunta a garantizar la subsistencia; y estas son todas formas bastante características de una política que, como política, anda al filo de una política democrática...

Luchar por la subsistencia ha ocupado todo el tiempo a los sectores sociales vulnerables. Obsesionados por la subsistencia, los pobres han dedicado sus mejores esfuerzos a procurarse las condiciones básicas de vida: pan, techo y abrigo. Muy pocas facetas de lo "público" estarán entre sus intereses dominantes. Abrumadas por la miseria, la misma libertad política podría no tener gran significado para la inmensa mayoría de la población. Dada estas condiciones de vida, grandes masas de población quedaran "fuera de la luz que irradia la esfera pública". Esta apreciación, enunciada a partir de Sobre la revolución de Hannah Arendt, parece efectiva .

Creo que un proceso social como la colonización y la descolonización puede ser de ayuda aquí. Es posible que el modelo de desarrollo asumido pueda asimilarse a un raro proceso de colonización de la población: las 'privatizaciones' iniciadas en las segunda mitad de los setenta y desarrolladas intensamente en los ochenta, implicaron extirpar la soberanía de los ciudadanos sobre todos los ámbitos privatizados. Todo lo que en otras época era un derecho se vuelve ahora una mercancía y el mercado es el que manda; los ciudadanos ya no son tales, son consumidores. Sus derechos son tan extensos como 
sea su capacidad de pago. Y han vivido colonizados por una elite, con sus derechos en estado de animación suspendida. Todo lo que han alcanzado es lo que 'les tocó', una ciudadanía de segunda clase... Y esa vida tan limitada agota e irrita.

Hoy la palabra de orden parece ser la descolonización. De alguna manera hemos vuelto atrás. Presumíamos haber avanzado mucho hacia la modernidad y la OECD y de improviso nos encontramos en una batalla por la independencia en la que los colonizados recuperan su voz, aparecen de nuevo los indios (los que fueron colonizados en su origen y su situación -cambios más y cambios menos- siguió siendo muy parecida) y la ciudad empieza a parecerse a los terrenos baldíos de antaño. Rodrigo Karmy, recordando un comentario de Armando Uribe a unos recuerdos de Eduardo Frei Montalva, hace ver que los 'indios' debieran permanecer siempre tras el Bío Bío. "La máquina mitológica de una oligarquía blanca e hispánica que despreció a los indios desde la Colonia, no ha dejado de despreciar al pueblo en su fase republicana- Indio y pueblo yuxtapuestos en una intensidad irreductible que habita los bordes del orden y que, de vez en cuando, irrumpe en las superficies..."

Es notable la profusión de banderas mapuches, junto con la chilena, en todas las manifestaciones de estos días; hay una icónica foto de los manifestantes sobre el monumento de Baquedano en que, contra un fondo anaranjado de incendios o del atardecer, destaca una wenüfoye. Y a esta descolonización recuperar derechos y soberanía- se procede de una manera agresiva. ¿Cómo recuperar derechos? Excluidos de la política, no han tenido arte ni parte en ella; no ha sido su campo por más de treinta años...

Hoy una lluvia de piedras y de palabras cae sobre las calles de Santiago, y de la noche a la mañana grandes segmentos de nuestra población se vuelven políticos: hay palabras por todas partes (en las paredes, en las estatuas, en la televisión, en los computadores) y su abundancia, tantas como las piedras, es otra señal de su vieja exclusión. ¿Como explicar la profusión de palabras en la calle? La lucha política requiere de una poderosa afirmación inicial, aunque sea en términos negativos: no más AFP!, no más CAE!, no más edificios! (como leí en una calle de Viña del Mar en las vallas en que se promocionaba la venta de departamentos nuevos cerca del Hospital Fricke). Hay que atraer a la gente, hay que organizar la protesta, pero también hay que juntar piedras...

Hoy muchos tiran piedras; su fuerte es su fuerza física Sin embargo, en la piedra lanzada también podría ir condensada una reflexión política. Se requiere atención y presteza para esquivarla físicamente; se requiere igualmente atención, pero además una muy difícil y compleja reflexión para interpretarla adecuadamente.

Frantz Fanon puede venir en nuestra ayuda. En su clásica "Los condenados de la tierra", proporciona una compleja visión del mundo colonial y del proceso de descolonización: "El mundo colonial es un mundo en compartimientos"; "el mundo colonizado es un mundo cortado en dos. La línea divisoria, la frontera está indicada por los cuarteles y las delegaciones de policía." La violencia, obviamente, está en el centro de este mundo: “¿Qué es pues esa violencia? Ya lo hemos visto: es la intuición que tienen las masas colonizadas de que su liberación debe hacerse, y no puede hacerse más que por la fuerza... la violencia, y ahí está el escándalo, puede constituir, como método, la consigna de un partido político." Por otra parte, los condenados de la tierra -salvando las diferencias de tiempo y lugar (y el uso irónico del lenguaje en Fanon)- tienen un gran parecido con nuestros 'protestantes' "Entonces los rufianes, los granujas, los desempleados, los vagos, atraídos se lanzan a la lucha de liberación como robustos trabajadores. Esos vagos, esos desclasados van a encontrar, por el canal de la acción militante y decisiva, el camino de la nación. No se rehabilitan en relación con la sociedad colonial, ni con la moral del dominador. Por el contrario, asumen su incapacidad para entrar en la ciudad salvo por la fuerza de la granada o del revólver. Esos desempleados y esos subhombres se rehabilitan en relación consigo mismos y con la historia. ...todas y todos los que oscilan entre la locura y el suicidio van a reequilibrarse, a actuar y participar de manera decisiva en la gran procesión de la nación que despierta."

Michel Foucault, en un texto al que volveré más adelante, señala que "el hombre que se subleva queda, en definitiva, fuera de la historia." Entiendo que 'sublevarse' trata de una apuesta tremendamente arriesgada, en que se pone en juego la vida misma (y es en ese sentido que queda fuera de la historia, que es una ruptura, para MF). La historia puede explicar el someterse, pero al sublevarse irrumpe 
una 'novedad', irrumpe otro sentido. La normalidad de la vida es puesta entre paréntesis (la normalidad es un privilegio, como leí en alguna pared de Providencia). Viendo la alegría de los muchachos cuando deshacen nuestra querida ciudad, no puedo menos que pensar si -contradiciendo a la Arendt, pero manteniéndome en sus propios términos- al hacerlo ¿no estarán teniendo acceso a la "felicidad pública"? ¿no estarán en contacto pleno con "la luz que irradia la esfera pública"?

\section{III.}

"...creo que nunca se puede comprender bien algo hacia lo cual uno es hostil" dice en el texto recién citado Michel Foucault, al tratar de explicar su actitud hacia las revueltas en Iran en 1978, que originarán una represión horrible (entre 2000 y 4000 muertos en una semana) y terminarán en un regimen religioso autoritario. Luego, señala que los procesos revolucionarios en el tercer mundo "van a tratar de arraigarse cada vez más en el fondo cultural de esos países..." (a diferencia con lo que ha sido clásico en la experiencia y reflexión occidental: desarrollo y organización de la clase obrera, conciencia de clase, el partido como vanguardia del proletariado, etc. etc.). Por este motivo Foucault observa que "resultará necesario dar un poco de crédito y prestar atención a lo que pasa..." (p. 54).

Esta entrevista data de agosto de 1979 y fue realizada por Fared Sassine, un intelectual libanés. Es una entrevista fascinante por varios motivos. Por un lado, sorprende las similitudes y las diferencias de la situación que origina estas reflexiones y las de su lectura actual 40 años después; sorprende igualmente la sensatez metodológica de Foucault: la dificultad de comprender aquello hacia lo que uno es hostil y la necesidad de prestar atención y darle crédito a lo que ocurre, al acontecimiento, más allá de las situaciones estructurales. En tercer término, sorprende también ver ese pensamiento ocurriendo. En numerosas ocasiones Foucault señala no estar seguro de alguna apreciación, que sería necesario reflexionar algo más sobre un punto específico, que tentativamente es posible afirmar que... Es decir, es una entrevista que ayuda a pensar en esos sesenta y tantos días transcurridos en Santiago.

Educado en el marxismo silvestre del siglo XX chileno, debo confesar que he visto lo ocurrido en San- tiago a partir del viernes 18 de octubre con bastante perplejidad y cierta cuota de aversión. Confío en los tiempos por venir, pero a la vez me preocupan algunos rasgos que ya se insinúan. Partiendo de la base de que no hay una sola manera de ser razonable, reconozco y creo que el diálogo es imprescindible, pero a la vez que cuando la violencia impera se ha perdido todo.

\section{REFERENCIAS BIBLIOGRÁFICAS}

1. Joaquín Lavín. Chile: la revolución silenciosa. Editora Zig-Zag, Santiago de Chile 1987.

2. Hannah Arendt. Sobre la revolución. Alianza Editorial, Madrid (2ª reimpresión), 2009.

3. Rodrigo Karmy. "Los indios de Chile", en Palabra Popular, Nº16 noviembre-diciembre 2019: 103-104.

4. Frantz Fanon. Los condenados de la tierra, Fondo de Cultura Económica, $7^{a}$ reimpresión 1983, p 65

5. Michel Foucault. Sublevarse, entrevista inédita con Faréd Sassine. Catálogo Libros, Viña del Mar Chile 2016 (segunda reimpresion junio 2019). 